\title{
DESEMPENHO DE EQUIPAMENTOS UTILIZADOS PARA O FECHAMENTO DE TAIPAS ABERTAS PARA DRENAGEM NO ARROZ IRRIGADO
}

Doi:http://dx.doi.org/10.1590/1809-4430-Eng.Agric.v35n5p875-885/2015

\section{ULISSES G. FRANTZ ${ }^{1}$, JOSÉ F. SCHLOSSER ${ }^{2}$, FABRÍCIO A. RODRIGUES ${ }^{3}$, MARCELO S. DE FARIAS ${ }^{4}$, JUAN P. BARBIERI ${ }^{5}$}

RESUMO: Na semeadura do arroz irrigado, é necessária a boa drenagem da área, sendo realizados drenos cortando as taipas transversalmente. Para o estabelecimento da lâmina de irrigação definitiva, é necessário o fechamento destes drenos realizado pelos agricultores por meio de diversas maneiras. O estudo de tempos e movimentos de diferentes operações agrícolas é uma importante ferramenta para a obtenção de dados que reflitam o desempenho das mesmas. Dessa forma, o presente trabalho objetivou avaliar o desempenho de cinco equipamentos utilizados na lavoura orizícola, na operação de fechamento de taipas abertas para drenagem (entaipadora de base larga, braço valetador, caçamba "scraper", pá de corte e um protótipo desenvolvido para realizar esta operação), em duas diferentes áreas (coxilha e várzea). Após a avaliação, verificou-se que há diferenças entre os equipamentos utilizados, sendo o protótipo superior aos demais para as variáveis tempo total de operação, eficiência de tempo sem tempo gasto com deslocamento entre taipas, capacidade efetiva de campo e consumo de combustível por taipa.

PALAVRAS-CHAVE: drenos, lavoura orizícola, eficiência.

\section{PERFORMANCE OF EQUIPMENT USED TO CLOSE OPENED EARTH DIKES OF DRAINAGE IN IRRIGATED RICE CROPS}

\begin{abstract}
A good drainage system is critical during irrigated rice sowing; therefore, earth dikes are built to control water flows. Therefore, irrigation depths can be regulated by these dikes' openings, being performed in a variety of ways. Studying time and motion of different agricultural practices consists of a meaningful tool to gather data on the performance of these mechanisms. Given that, we aimed to test the performance of five equipment used in paddies to close earth dikes opened for drainage purposes (rice-dike plow, ditcher, bucket scraper, cutting shovel and a prototype developed for this operation) in two different areas (hills and lowland). After evaluation, we concluded that there are differences among the assessed equipment and, the developed prototype had the best results for total time of operation, time efficiency, effective field capacity and fuel consumption by dike.
\end{abstract}

KEYWORDS: drains, paddy farming, efficiency.

\section{INTRODUÇÃO}

O Estado do Rio Grande do Sul - RS, é o maior produtor de arroz irrigado do Brasil, tendo contribuído na safra de 2012/2013, com 67\% da produção nacional (CONAB, 2013). O sistema de cultivo predominante é o cultivo mínimo $(74,8 \%)$, seguido do sistema convencional em linha $(12,6 \%)$, pré-germinado $(12,2 \%)$ e convencional a lanço $(0,4 \%)$ (IRGA, 2013). A utilização das

\footnotetext{
${ }^{1}$ Eng ${ }^{o}$ Agrônomo, Prof. Doutor, Universidade Federal do Pampa (UNIPAMPA), Campus Dom Pedrito/Dom Pedrito RS, ulissesgf@hotmail.com

${ }^{2}$ Eng ${ }^{\circ}$ Agrônomo, Prof. Doutor, Departamento de Engenharia Rural, Universidade Federal de Santa Maria (UFSM)/Santa Maria - RS, josefernandoschlosser@gmail.com

${ }^{3}$ Eng $^{\circ}$ Agrônomo, Mestre em Engenharia Agrícola, fabricioazevedorodrigues@ hotmail.com

${ }^{4}$ Eng $^{\mathbf{o}}$ Agrônomo, Doutorando em Engenharia Agrícola, Programa de Pós-Graduação em Engenharia Agrícola, Universidade Federal de Santa Maria (UFSM)/Santa Maria - RS, silveira_farias@ hotmail.com

${ }^{5}$ Eng $^{\circ}$ Agrônomo, Mestrando em Engenharia Agrícola, Programa de Pós-Graduação em Engenharia Agrícola, Universidade Federal de Santa Maria (UFSM)/Santa Maria - RS, barbieri.juan@ @otmail.com
} 
áreas de várzea para cultivo do arroz irrigado é diversificada, podendo ser utilizadas com associação do cultivo de arroz com pecuária de corte e/ou rotação de culturas, principalmente soja (MASSONI et al., 2013).

A lavoura de arroz no Rio Grande do Sul diferencia-se de outras culturas pela necessidade de tecnificação em seus processos de preparo e cultivo, dentre as quais está a sistematização da área, a qual é um processo de adequação da superfície do terreno para deixá-lo apto ao cultivo de arroz.

A sistematização com nivelamento da superfície do solo em desnível (SNSSD) é predominante nas áreas, assim como os sistemas de cultivo que utilizam a semeadura em solo seco, como o sistema convencional e o cultivo mínimo. Esse sistema exige a montagem de estruturas de contenção da água de irrigação, que são camalhões com mesmo nível em toda sua extensão (denominadas popularmente de taipas ou marachas no RS), e são conformadas com implementos denominados de entaipadoras, as quais retiram e acumulam solo da própria área de cultivo. Para esse processo de sistematização, após o preparo do solo, é necessário que se faça o entaipamento prévio através de taipas com dimensões que variam de 1,30 a $1,70 \mathrm{~m}$ para largura, 0,20 a $0,90 \mathrm{~m}$ para a largura do leiveiro e 0,13 a $0,26 \mathrm{~m}$ para altura.

Na semeadura em solo seco, há necessidade de ter uma boa drenagem da área. Assim, são conformados drenos na área de cultivo (através de valetadoras), que cortam as taipas transversalmente e permanecem até o momento de estabelecimento da lâmina de irrigação definitiva, o qual geralmente coincide com o último tratamento em solo seco, que é a aplicação da adubação nitrogenada no estádio vegetativo V3/V4 da cultura. Neste momento, é necessário o fechamento dos drenos, o que é realizado pelos produtores utilizando diversos meios, constituindo-se em um processo de baixa capacidade operacional, sendo necessária a quantificação de seu desempenho.

As informações sobre o desempenho e a capacidade de trabalho das máquinas agrícolas, em cada fase de operação, são de grande importância no gerenciamento de sistemas mecanizados agrícolas, auxiliando na tomada de decisões (MOLIN et al., 2006). Ainda, a obtenção dessas informações é normalmente realizada por meio da análise dos tempos e movimentos.

O estudo de tempos e movimentos tem grande importância como ferramenta de auxílio para o dimensionamento adequado da produção, possibilitando identificar os elementos componentes da operação, melhoria dos métodos e posterior fixação do tempo-padrão (SIMÕES \& SILVA, 2010). Esses estudos são realizados para que possibilitem aumentar a capacidade em horas produtivas, reduzindo as horas improdutivas, buscando saber qual equipamento teve, em horas efetivas, maior desempenho (SIMÕES \& SILVA, 2012; SIMÕES et al., 2011).

Conforme TOLEDO et al. (2010), as operações agrícolas mecanizadas devem ser planejadas de forma racional para que haja aumento da rentabilidade no campo. Dessa forma, autores como MOLIN et al. (2011), MACHADO et al. (2010), REYNALDO \& MOLIN (2011), SIMÕES et al. (2011) e FIORESE et al. (2011) propuseram metodologias para avaliação de operações, custos e equipamentos agrícolas, com o intuito de um manejo mais eficiente.

Diante disto, este estudo teve como objetivo avaliar o desempenho de cinco diferentes equipamentos utilizados na lavoura orizícola para a operação de fechamento de taipas abertas para drenagem, em duas diferentes áreas com SNSSD. Como objetivos específicos, buscou-se determinar o tempo total de operação, eficiências de tempo, capacidade efetiva de campo e consumo de combustível por ciclo de fechamento de taipas abertas para drenagem.

\section{MATERIAL E MÉTODOS}

A fim de realizar a avaliação a campo, adaptou-se uma metodologia de avaliação para o estudo de tempos necessários para o fechamento das taipas abertas para drenagem dos diferentes tratamentos, que primeiro consistiu no estudo orgânico das atividades executadas para o fechamento das taipas. Em um segundo momento, estabeleceu-se a forma como os dados seriam adquiridos e como seria a mensuração. 


\section{Descrição dos equipamentos e as atividades realizadas}

No estudo, foram comparados dois métodos, manual (pá de corte) e mecanizado. No método mecanizado, os equipamentos submetidos à avaliação foram caçamba "scraper" (marca Masal com capacidade máxima de 3,0 $\mathrm{m}^{3}$ ), entaipadora de base larga (marca Boelter modelo $\mathrm{N} 10$ ), braço valetador (marca Masal modelo BVM 2000) e um protótipo projetado e construído especialmente para esta operação, o qual não pode ser descrito nem ilustrado no referido trabalho, neste momento, em função de estar ocorrendo um pedido de depósito de patente.

Baseado no estudo da operação de fechamento de taipas abertas para drenagem e na experiência observada através da operação, foi elaborada a Tabela 1, que diz respeito aos diferentes tempos gastos pelos equipamentos durante a operação.

TABELA 1. Atividades demandadas nos processos manual e mecanizado, utilizadas para fechamento de taipas abertas para drenagem. Manual and mechanized procedures to close dike openings.

\begin{tabular}{|c|c|c|c|c|c|}
\hline Atividades & $\begin{array}{c}\text { Entaipadora de } \\
\text { base larga }\end{array}$ & $\begin{array}{l}\text { Caçamba } \\
\text { "scraper" }\end{array}$ & $\begin{array}{c}\text { Braço } \\
\text { valetador }\end{array}$ & Protótipo & $\begin{array}{l}\text { Pá de } \\
\text { corte }\end{array}$ \\
\hline Deslocamento entre taipas* & $X$ & $X$ & $X$ & $X$ & $\mathrm{X}$ \\
\hline $\begin{array}{c}\text { Deslocamento da taipa até o local } \\
\text { de coleta de solo e local de coleta } \\
\text { de solo até a taipa* }\end{array}$ & & X & & & \\
\hline Retirada de solo & & $X$ & & & \\
\hline Acumulação de solo & & $X$ & & & \\
\hline Retirada e acumulação de solo+ & $\mathrm{X}$ & & $\mathrm{X}$ & $X$ & $X$ \\
\hline Manobra $(\text { ré })^{*}$ & $X$ & & & & \\
\hline Manobras adicionais* & & $X$ & $X$ & & \\
\hline Compactar solo & $\mathrm{X}$ & $X$ & $\mathrm{X}$ & $X$ & $\mathrm{X}$ \\
\hline
\end{tabular}

*Tempos improdutivos; +Nesses equipamentos, a retirada e a acumulação são realizadas simultaneamente dentro da área de cultivo.

Entaipadora de base larga - Esse implemento desloca-se no mesmo sentido da taipa e retira o solo de áreas adjacentes da mesma (leiveiro), sendo necessários vários ciclos de retirada de solo para que se consiga uma quantidade suficiente para o fechamento do dreno (o que demanda manobras de ré). Além do deslocamento entre taipas, na entaipadora de base larga, a "retirada e a acumulação do solo" dizem respeito ao trajeto percorrido para retirada de solo e acumulação no dreno. A manobra de ré, refere-se ao deslocamento do conjunto para uma nova retirada e acumulação de solo, de forma a acumular um volume suficiente para realizar o fechamento. E a compactação do solo é realizada no sentido longitudinal da taipa através dos rodados do trator.

Caçamba "scraper" - Utiliza uma grande quantidade de solo (que pode ser usado para o fechamento de várias aberturas), e o local de coleta geralmente não está próximo aos drenos, sendo fora da área de cultivo. Assim, necessita das atividades de deslocamento até o local de coleta, retirada de solo e retorno até a taipa. O sentido de operação de solo é transversal à taipa, sendo a acumulação de solo (descarga do material coletado) e a compactação realizadas neste sentido. A compactação refere-se à pressão aplicada pelos rodados do conjunto durante o deslocamento sobre o solo depositado na abertura, o que é realizado transversalmente à taipa.

Braço valetador - Essa máquina é semelhante à parte traseira de uma retroescavadora, porém a mesma é acoplada a um trator agrícola. A operação é realizada com o mesmo posicionado parado muito próximo ao dreno e, assim, retira-se solo de áreas próximas a este. A retirada e a acumulação de solo e a compactação são efetuados pela concha desta máquina. Neste caso específico, "manobras adicionais" são aquelas necessárias para o operador deslocar-se do posto de operação da retroescavadeira, até o posto de operação do trator, e para levantar e abaixar as sapatas laterais de apoio ao solo. 
Protótipo - Implemento construído para realizar a operação de fechamento dos drenos nas taipas, o qual foi desenvolvido utilizando o modelo de referência para o processo de desenvolvimento de máquinas agrícolas (MRPDMA) de ROMANO (2013), sendo baseado nas necessidades dos clientes. O deslocamento efetuado pelo protótipo no mesmo sentido da taipa resulta na "retirada e na acumulação do solo", e ao mesmo tempo em que retira o solo, acumula no local do dreno. "Compactar solo" refere-se ao efeito da compactação realizada pelos pneus do trator no solo que foi depositado no dreno sobre a taipa e realizado no sentido longitudinal da mesma.

Pá de corte - Consiste numa operação manual de onde é removida uma pequena quantidade de solo das proximidades do dreno, sendo um procedimento que pode ser inferior em comparação com os sistemas mecanizados. "Retirada e acumulação de solo" é a retirada de solo, adentrando a pá de corte no solo e acumulando a porção retirada na abertura da taipa. "Compactar o solo" é a operação de compressão da porção de solo colocado sobre o dreno, executada com a face posterior da pá de corte.

\section{Avaliações:}

A aquisição da informação de tempo foi efetuada através da filmagem da operação durante um determinado número de ciclos de fechamento de taipas consecutivas. Posteriormente, assistindo ao vídeo, utilizando-se de meios de pausa e de continuação obtiveram-se os tempos gastos com deslocamento, manobras, total de operação, entre outros, de acordo com a Tabela 1. De posse dos dados referentes ao tempo gasto com determinada fase do ciclo de fechamento, os mesmos foram preenchidos na planilha eletrônica de dados, onde na linha superior eram dispostos os tempos que foram cronometrados na filmagem; e nas linhas subsequentes, os dados obtidos nos diferentes tratamentos.

Baseado nos dados obtidos, utilizou-se de uma série de variáveis e equações para avaliação do estudo de tempos gastos no fechamento das aberturas existentes nas taipas. Dividiu-se o tempo total de operação (Ttotal), [eq.(1)] em improdutivos (Timpr) e produtivos (Tpro); e estes, divididos conforme as eqs. (2) e (3).

A eficiência de tempo (Et) refere-se ao total de tempo em que o equipamento estava efetivamente realizando a operação, sendo obtido através da [eq. (4)]. Para saber apenas o tempo por ciclo de fechamento das taipas abertas para drenagem, descontado o tempo gasto com deslocamento entre taipas, utilizou-se da [eq. (5)]. A capacidade de campo efetiva (CeC) foi quantificada através da [eq. (6)].

Para a medida do consumo de combustível, utilizou-se da metodologia de completar-se o depósito de combustível dos tratores até o nível máximo; posteriormente, ligava-se o trator agrícola, executava-se a operação (mesmo trabalho de fechamento) e desligava-se o mesmo. O depósito era então reabastecido através de uma proveta graduada, com capacidade de um litro; e o volume gasto, anotado em uma planilha.

De posse desse dado, pode-se calcular o consumo de combustível horário (ConsHor) e o consumo de combustível por taipa (Cons Taipa) através das eqs. (7) e (8).

$$
\begin{aligned}
& \text { Ttotal }=\text { Timpr }+ \text { Tprod } \\
& \text { Timpr }=\sum \text { Tdet }+\sum \text { Tdtc }+\sum \text { Tmré }+\sum \text { Tmad } \\
& \text { Tprod }=\sum \operatorname{Trs}+\sum \text { Tas }+\sum \text { Treas }+\sum \operatorname{Tcs} \\
& \mathrm{Et}=\frac{\text { Ttotal }-(\text { Timpr) }}{\text { Ttotal }} 100 \\
& \text { Et semTdet }=\frac{(\text { Ttotal }-\Sigma T \text { det })-(\text { Timpro }-\Sigma T \text { det })}{(\text { Ttotal }- \text { ETdet })} \times 100 \\
& \mathrm{CeC}=\frac{\mathrm{n}^{0} \text { ciclos }}{\text { Timpr }+\mathrm{T}_{\text {prod }}}
\end{aligned}
$$




$$
\begin{aligned}
& \text { ConsHor }=\frac{\text { VolComb }}{\text { Ttotal }} \\
& \text { Cons Taipa }=\frac{\text { VolComb }}{\mathrm{n}^{a} \text { ciclos }}
\end{aligned}
$$

em que,

Ttotal - tempo total de operação é o tempo em que a máquina está executando alguma das atividades agrícolas (s);

Timpr - é o tempo despendido, no qual a máquina não está executando a tarefa agrícola de forma a contribuir para o aumento da capacidade de operação (s);

Tprod - é o tempo utilizado efetivamente para realizar a atividade agrícola (s);

Tdet - Tempo de deslocamento entre taipas (s);

Tdtc - Tempo de deslocamento da taipa até ao local de coleta de solo e de retorno (s);

Tmré - Tempo para realizar manobras de ré (s);

Tmad - Tempo para realizar manobras adicionais (s).

Trs - Tempo de retirada de solo (s);

Tas - Tempo de acumulação de solo (s);

Treas - Tempo de retirada e acumulação de solo (s);

Tcs - Tempo para compactar o solo (s).

Et - eficiência de tempo $(\%)$;

Et sem Tdet - eficiência de tempo descontado o tempo com deslocamento entre taipas (\%);

$\mathrm{CeC}$ - Capacidade de campo efetiva ( $\mathrm{n}^{\circ}$ de ciclos de fechamento de taipas abertas para drenagem por hora);

ConsHor - consumo de combustível horário $\left(\mathrm{L} \mathrm{h}^{-1}\right)$;

VolComb - volume de combustível consumido (L);

Cons Taipa - consumo de combustível por ciclo de fechamento de taipas abertas para drenagem $\left(\mathrm{L} \mathrm{taipa}^{-1}\right)$,

$\mathrm{n}^{\mathrm{o}}$ ciclos - número de ciclos de fechamento de taipas abertas para drenagem $\left(\mathrm{n}^{\mathrm{o}}\right)$.

\section{Delineamento experimental e tratamentos}

O delineamento experimental foi baseado em dois fatores (área e equipamentos), sendo duas áreas (várzea e coxilha) e cinco equipamentos para o fechamento das aberturas nas taipas, quatro utilizando operações mecanizadas (entaipadora de base larga, braço valetador, caçamba e protótipo) e uma operação manual (operação de pá de corte), constituindo-se o delineamento experimental de um bifatorial $2 \times 5$, em blocos ao acaso, com 4 repetições. Cada unidade experimental constituiu-se pelo ciclo de fechamento de uma abertura na taipa.

Os dados obtidos foram analisados pelo software científico SISVAR de FERREIRA (2011). Quando houve a interação entre área e forma de fechamento, os dados passaram por uma análise de diferenças de médias, através do teste de Tukey.

As taipas existentes na área possuíam uma altura de $0,20 \mathrm{~m}$ e uma abertura que totalizava 0,40 $\mathrm{m}$ de largura e $0,40 \mathrm{~m}$ de profundidade $(0,20 \mathrm{~m}$ da taipa e $0,20 \mathrm{~m}$ abaixo do nível do solo). Assim, o trabalho a ser realizado pelos equipamentos e em cada área era o mesmo, porém sem repetir a mesma taipa. A distância entre taipas na área de coxilha era de 4 metros; e na várzea, de 12 metros. 


\section{RESULTADOS E DISCUSSÃO}

A coleta dos dados possibilitou a obtenção de informações com maior detalhamento e menor possibilidade de erros, através da técnica de filmagem e posterior cronometragem.

Tempo total de operação (Ttotal) - Houve interação entre os fatores Área e Equipamentos, ou seja, o uso de diferentes locais de aplicação e formas de fechamento do sulco na taipa alterou o tempo total de operação (Tabela 2).

TABELA 2. Tempo total de operação (Ttotal) demandado pelos diferentes equipamentos para fechamento de aberturas nas taipas. Total time of operation $\left(\mathbf{T}_{\text {total }}\right)$ required by the different equipment used to close dike openings.

\begin{tabular}{lcc}
\hline \multirow{2}{*}{ Equipamentos para fechamento } & \multicolumn{2}{c}{ Tempo total de operação (s taipa ${ }^{-1}$ ) } \\
\cline { 2 - 3 } & Coxilha & Várzea \\
\hline Entaipadora de base larga & $40,25 \mathrm{bA}$ & $46,75 \mathrm{bB}$ \\
Caçamba "scraper" & $85,25 \mathrm{cA}$ & $97,75 \mathrm{~dB}$ \\
Braço valetador & $102,00 \mathrm{dA}$ & $136,00 \mathrm{eB}$ \\
Pá de corte & $50,75 \mathrm{bA}$ & $59,25 \mathrm{cB}$ \\
Protótipo & $26,50 \mathrm{aA}$ & $32,00 \mathrm{aB}$ \\
\hline CV & & $8,09 \%$
\end{tabular}

Médias seguidas da mesma letra minúscula na vertical e maiúscula na horizontal não diferem a 5\% de significância, pelo teste de Tukey.

Quando o processo foi realizado na área de coxilha, o protótipo obteve o menor tempo para o ciclo de fechamento, diferindo estatisticamente da entaipadora de base larga (40,25 s ciclo de fechamento $\left.^{-1}\right)$ e da pá de corte $\left(50,75 \mathrm{~s}\right.$ ciclo de fechamento $\left.{ }^{-1}\right)$, as quais não diferiram entre si. A caçamba "scraper" obteve o tempo de fechamento de 85,25 s ciclo de fechamento ${ }^{-1}$, diferindo dos anteriores e do braço valetador $\left(102,00 \mathrm{~s}^{\text {ciclo de fechamento }}{ }^{-1}\right)$. No caso do protótipo, esse menor tempo é devido que ao mesmo tempo em que retira o solo, ele o acumula e, então faz-se o direcionamento deste sobre a abertura; com isso, realiza-se o fechamento com apenas uma movimentação frontal, proporcionando maior capacidade para o mesmo. Diferentemente, a entaipadora de base larga necessita fazer um deslocamento frontal acumulando, e depois uma manobra à ré para retirar mais solo para depositá-lo sobre a abertura, o que aumenta o tempo total de operação. No caso da pá de corte, o maior tempo demandado é para retirada e acumulação de solo, porém não possui tempos de manobras. No caso da caçamba "scraper", a maior parte do tempo é gasto com a retirada de solo, a qual é realizada fora da área de cultivo e a acumulação de solo, sendo necessário que este implemento seja direcionado transversalmente à taipa e em cima da abertura, e através de fluxo hidráulico há a liberação de solo para a abertura o que é um processo lento. A menor capacidade (braço valetador) é devido ao maior tempo despendido com a realização da atividade de retirada e de acumulação de solo, que é superior aos demais.

$\mathrm{Na}$ operação na área de várzea, todos os tratamentos diferiram entre si, ficando com o menor tempo o protótipo $\left(32,00 \mathrm{~s}\right.$ ciclo de fechamento $\left.{ }^{-1}\right)$, seguido da entaipadora de base larga, pá de corte, caçamba "scraper" e braço valetador $\left(136,00 \mathrm{~s}\right.$ ciclo de fechamento $\left.{ }^{-1}\right)$. No caso da área de várzea ocorrem os mesmos motivos para os diferentes equipamentos.

Quando todos os tratamentos foram aplicados na área de coxilha e de várzea, diferiram significativamente entre si no que se refere aos tempos. Isso pode ser devido ao maior tempo gasto com deslocamento entre taipas que ocorreu na área de várzea, devido à maior distância entre taipas.

Eficiência de tempo (Et) - Também, da mesma forma que para a variável anterior, encontrou-se interação entre os fatores área e formas de fechamento, ou seja, o uso de diferentes áreas alterou o tempo total de operação quando se utilizam diferentes tratamentos; assim, as variáveis tiveram de ser analisadas em conjunto (Tabela 3 ). 
TABELA 3. Eficiência de tempo (Et) para os diferentes equipamentos para fechamento de aberturas nas taipas. Time efficiency $(\mathrm{Et})$ of the different equipment used to close dike openings.

\begin{tabular}{lcc}
\hline \multicolumn{1}{c}{ Equipamentos para fechamento } & \multicolumn{2}{c}{ Eficiência de tempo (\%) } \\
Coxilha & Várzea \\
\hline Entaipadora de base larga & $50,56 \mathrm{dA}$ & $35,95 \mathrm{~dB}$ \\
Caçamba "scraper" & $32,14 \mathrm{eA}$ & $28,90 \mathrm{dA}$ \\
Braço valetador & $77,47 \mathrm{bA}$ & $69,49 \mathrm{bB}$ \\
Pá de corte & $90,13 \mathrm{aA}$ & $77,57 \mathrm{aB}$ \\
Protótipo & $61,18 \mathrm{cA}$ & $48,53 \mathrm{cB}$ \\
\hline CV & \multicolumn{3}{c}{$6,30 \%$} \\
\hline
\end{tabular}

Médias seguidas da mesma letra, minúscula na vertical e maiúscula na horizontal, não diferem a 5\% de significância, pelo teste de Tukey.

Para a área de coxilha, todos os tratamentos diferiram entre si no que se refere à eficiência de tempo, sendo a maior eficiência obtida com a pá de corte $(90,13 \%)$, seguida do braço valetador, protótipo, entaipadora de base larga e caçamba "scraper" (32,14\%). Com um foco distinto da operação realizada neste trabalho, mas a fim de elucidar alguns números, na operação de colheita mecanizada de arroz, ARALDI et al. (2013) encontraram eficiência de tempo média de 75,7\%, já na operação de extração de madeira, SIMÕES \& FENNER (2010) encontraram eficiência operacional de $82,21 \%$. Conforme OLIVEIRA et al. (2009), a eficiência operacional é o percentual de tempo efetivamente trabalhado.

A maior eficiência de tempo ocorre na pá de corte, em função de que o único tempo improdutivo existente é o de deslocamento entre taipas, diferentemente dos outros equipamentos utilizados. Já a caçamba "scraper" possui a pior eficiência percentual, devido ao maior tempo improdutivo existente para este implemento, pois além de os tempos gastos serem semelhantes aos dos outros equipamentos, este ainda possui o tempo para se deslocar até o local de coleta do solo. O fato de o braço valetador ter maior eficiência, mesmo tendo maior tempo gasto para fechamento que todos os outros, deve-se ao fato de que a maior parte do tempo gasto é produtivo, uma vez que o tempo gasto com manobras adicionais e deslocamento entre taipas é relativamente menor que o tempo produtivo.

$\mathrm{Na}$ área de várzea, os únicos tratamentos que não diferiram estatisticamente entre si foram a entaipadora de base larga e a caçamba "scraper", sendo que isso é devido ao tempo gasto com deslocamento, para retirada de solo e a deposição de solo pela caçamba, pois uma vez carregada, esta tem apenas os tempos de acumulação de solo e deslocamento entre taipas menor que os da entaipadora.

Comparando as diferentes áreas, as mesmas diferiram em todos os tratamentos, menos no que se refere à aplicação da caçamba "scraper", o que é devido ao tempo com "deslocamento da taipa até ao local de coleta de solo e retorno", e a "retirada de solo" ter sido praticamente o mesmo em ambas as áreas, porém ocorrendo maior tempo para a "compactação do solo", uma vez que a compactação, para este equipamento, é realizada através da pressão aplicada pelos rodados do conjunto durante o deslocamento (transversal à taipa) sobre o solo depositado na abertura.

Eficiência de tempo sem tempo de deslocamento entre taipas (Et sem Tdet) - Para esta variável, ocorreu interação entre os fatores área e formas de fechamento, ou seja, o uso de diferentes áreas alterou a eficiência de tempo sem o tempo de deslocamento entre taipas, quando se utilizaram diferentes implementos, assim as variáveis foram analisadas em conjunto (Tabela 4). 
TABELA 4. Eficiência de tempo sem o tempo gasto com deslocamento (Et sem Tdet) para os diferentes equipamentos para fechamento de aberturas nas taipas. Time efficiency without travel time (Et sem Tdet) of the different equipment used to close dike openings.

\begin{tabular}{lcc}
\hline \multicolumn{1}{c}{ Equipamentos para fechamento } & \multicolumn{2}{c}{ Et sem Tdet (\%) } \\
& Coxilha & Várzea \\
\hline Entaipadora de base larga & $66,52 \mathrm{cA}$ & $65,10 \mathrm{cA}$ \\
Caçamba "scraper" & $37,26 \mathrm{dA}$ & $36,63 \mathrm{dA}$ \\
Braço valetador & $92,68 \mathrm{bA}$ & $80,93 \mathrm{bB}$ \\
Pá de corte & $100,00 \mathrm{aA}$ & $100,00 \mathrm{aA}$ \\
Protótipo & $100,00 \mathrm{aA}$ & $100,00 \mathrm{aA}$ \\
\hline CV & \multicolumn{2}{c}{$4,34 \%$} \\
\hline
\end{tabular}

Médias seguidas da mesma letra, minúscula na vertical e maiúscula na horizontal, não diferem a 5\% de significância, pelo teste de Tukey.

O comportamento dos equipamentos na área de coxilha e na área de várzea foi o mesmo obtido nas demais variáveis. Assim, a eficiência de tempo, sem o tempo gasto com deslocamento, foi maior para o protótipo e a pá de corte que não diferiram estatisticamente entre si. Este fato devese a que, no processo realizado por ambos, todos os tempos são produtivos se for descontado o tempo gasto com deslocamento. O braço valetador, no entanto ( $3^{\mathrm{a}}$ maior eficiência), diferiu dos dois anteriores e da entaipadora de base larga ( $4^{\text {a }}$ maior eficiência), a qual também diferiu da caçamba "scraper" (37,26\%). Nesse sentido, o tempo gasto com manobras e manobras adicionais foi maior para o braço valetador, seguido da entaipadora de base larga e caçamba "scraper", contribuindo para esse resultado.

Comparando o mesmo tratamento para as diferentes áreas, estas apenas diferiram entre si para o tratamento caçamba "scraper". Tal fato deve-se aos tempos gastos com "deslocamento da taipa até ao local de coleta de solo e de retorno", e a "retirada de solo" ter sido praticamente o mesmo em ambas as áreas, uma vez que, nesse caso, o solo é coletado do mesmo local (para ambas as áreas) e fora da área de cultivo, a uma mesma distância deste.

Capacidade efetiva de campo (CeC) - Ocorreu interação entre os fatores avaliados, ou seja, o uso de diferentes áreas alterou a capacidade efetiva de campo, quando se utilizaram diferentes equipamentos (Tabela 5).

TABELA 5. Capacidade efetiva de campo $(\mathrm{CeC})$ para os diferentes equipamentos para fechamento de aberturas nas taipas. Effective field capacity (CeC) of the different equipment used to close dike openings.

\begin{tabular}{lcc}
\hline \multicolumn{1}{c}{ Equipamentos para fechamento } & \multicolumn{2}{c}{ CeC (ciclo de fechamento $\mathbf{~ h}^{-1}$ ) } \\
Coxilha & Várzea \\
\hline Entaipadora de base larga & $89,76 \mathrm{bA}$ & $77,25 \mathrm{bB}$ \\
Caçamba "scraper" & $42,32 \mathrm{dA}$ & $36,83 \mathrm{dA}$ \\
Braço valetador & $35,42 \mathrm{dA}$ & $26,64 \mathrm{eB}$ \\
Pá de corte & $70,95 \mathrm{cA}$ & $61,42 \mathrm{cB}$ \\
Protótipo & $136,26 \mathrm{aA}$ & $112,55 \mathrm{aB}$ \\
\hline CV & \multicolumn{3}{c}{$7,01 \%$} \\
\hline
\end{tabular}

Médias seguidas da mesma letra, minúscula na vertical e maiúscula na horizontal, não diferem a 5\% de significância, pelo teste de Tukey.

$\mathrm{Na}$ área de coxilha, quase todos os equipamentos diferiram entre si, sendo a maior capacidade efetiva de campo conseguida com o protótipo, e os piores, que não diferiram entre si, para caçamba "scraper" e braço valetador. Essa menor capacidade da caçamba e do braço valetador deve-se ao maior tempo que é gasto para realizar a operação de fechamento. No caso da caçamba, a acumulação de solo tem um tempo elevado em função de esta ter de ficar sobre a abertura na taipa 
para poder acumular o solo no local. Já para o braço valetador, esse é o tempo para a concha de retirada posicionar o solo retirado sobre a abertura.

$\mathrm{Na}$ área de várzea, assim como ocorreu na coxilha, a maior capacidade de trabalho ocorreu com o protótipo, que diferiu significativamente da entaipadora de base larga, a qual diferiu da pá de corte, da caçamba "scraper", e essa, do braço valetador. No caso do protótipo, apenas com uma movimentação em seu sentido de deslocamento à frente, realiza o fechamento, proporcionando a maior capacidade para o mesmo. Diferentemente, a entaipadora de base larga necessita fazer um deslocamento frontal acumulando, e depois uma manobra à ré para retirar mais solo para depositá-lo sobre a abertura. No caso da pá de corte, o maior tempo demandado é para retirada e acumulação de solo, diminuindo a capacidade efetiva. A menor capacidade (braço valetador) devese ao maior tempo despendido com a realização da atividade de retirada e de acumulação de solo do que os demais.

Quando o mesmo tratamento foi aplicado nas diferentes áreas, houve diferença significativa da área de coxilha para a de várzea, em todos os tratamentos, com exceção da caçamba "scraper", sendo os valores maiores na área de coxilha do que na várzea, fato este devido à menor distância entre taipas do primeiro, que proporciona menor tempo gasto com deslocamento.

Consumo de combustível por taipa (Cons Taipa) - Ocorreu interação entre os fatores área e formas de fechamento, ou seja, o uso de diferentes áreas alterou o consumo de combustível por taipa quando se utilizaram diferentes implementos (Tabela 6).

TABELA 6. Consumo de combustível por ciclo de fechamento (Cons Taipa) para os diferentes equipamentos para fechamento de aberturas nas taipas. Fuel consumption per closing cycle (Cons Taipa) of the different equipment used to close dike openings.

\begin{tabular}{lcc}
\hline \multicolumn{1}{c}{ Equipamentos para fechamento } & \multicolumn{2}{c}{$\begin{array}{c}\text { Cons Taipa }(\text { c ciclo de fechamento } \\
\text { Coxilha }\end{array}$} \\
Vnárzea
\end{tabular}

Médias seguidas da mesma letra, minúscula na vertical e maiúscula na horizontal, não diferem a 5\% de significância, pelo teste de Tukey.

$\mathrm{Na}$ área de coxilha, o consumo de combustível do braço valetador, do protótipo e da entaipadora de base larga não diferiu estatisticamente entre si. Porém, diferiram estatisticamente da caçamba "scraper".

$\mathrm{Na}$ área de várzea, o protótipo obteve o menor consumo de combustível por taipa, diferindo estatisticamente da entaipadora de base larga e do braço valetador, onde os dois últimos não diferiram estatisticamente entre si. Isto deve-se a dois fatores: tempo necessário para realizar a operação e demanda energética. Para o primeiro, esse tempo no braço valetador é maior que o da caçamba, o qual é maior que o da entaipadora, e esta, do protótipo (Tabela 2). Um segundo fator e que pode ter impactado para o resultado é a demanda energética por parte da caçamba ser maior que os demais para a retirada de solo e deslocamento até ao local de coleta, e no caso da entaipadora de base larga, em função da demanda pelos discos da mesma.

Quando comparados todos os tratamentos dentro de cada área, para a caçamba, o consumo na área de coxilha e de várzea não diferiu entre si. No entanto, para a entaipadora de base larga, braço valetador e protótipo, houve diferença significativa entre a área de coxilha e área de várzea, sendo os maiores valores encontrados na várzea. Tal situação é devida a maior distância percorrida em relação ao deslocamento entre taipas. 


\section{CONCLUSÕES}

Esse experimento proporcionou verificar diferenças entre os equipamentos utilizados para a operação de fechamento de taipas abertas para drenagem, onde o protótipo se mostrou superior aos demais para as variáveis tempo total de operação, eficiência de tempo sem tempo, gasto com deslocamento entre taipas, capacidade efetiva de campo e consumo de combustível por taipa.

\section{AGRADECIMENTOS}

Os autores agradecem ao apoio financeiro da Coordenação de Aperfeiçoamento de Pessoal de Nível Superior (CAPES) e Conselho Nacional de Desenvolvimento Científico e Tecnológico (CNPq). Também, ao CNPq pela bolsa de produtividade em pesquisa do segundo autor.

\section{REFERÊNCIAS}

ARALDI, P. F.; SCHLOSSER, J. F.; FRANTZ, J. F.; RIBAS, R. L.; SANTOS, P. M. Eficiência operacional na colheita mecanizada em lavouras de arroz irrigado. Ciência Rural, Santa Maria, v.43, n.3, p.445-451, mar. 2013. Disponível em: <http://www.scielo.br/pdf/cr/v43n3/a8213cr6530.pdf>. Acesso em: 10 set. 2014.

CONAB - Companhia Nacional de Abastecimento. Acompanhamento da safra brasileira de grãos. Décimo Segundo Levantamento - Setembro de 2013. Disponível em: <http://www.conab.gov.br/OlalaCMS/uploads/arquivos/13_09_10_16_05_53_boletim_portugues_s etembro_2013.pdf>. Acesso em: 10 set. 2014.

FERREIRA, D.F. SISVAR: A computer statistical analysis system. Ciência e Agrotecnologia, Lavras, v.35, n.6, p.1039-1042. 2011. Disponível em: <http://dx.doi.org/10.1590/S1413$70542011000600001>$. Acesso em: 10 set. 2014.

FIORESE, D. A.; GOMES, L. F. S.; SOUZA, S. N. M.; DALLMEYER, A. U.; ROMANO, L. N. Metodologia experimental para avaliação de custos de produção e utilização de biodiesel: estudo de caso de quatro ésteres metílicos e óleo diesel comercial. Ciência Rural, Santa Maria, v.41, n.11, nov. 2011. Disponível em: <http://dx.doi.org/10.1590/S0103-84782011001100012>. Acesso em: 10 set. 2014.

IRGA - Instituto Rio Grandense do arroz. RS - Sistemas de cultivo - safra 2012/2013. Porto Alegre, 2013. Disponível em: <http://www3.irga.rs.gov.br/uploads/anexos/1370133557Sistemas_cultivo_quadro.pdf>. Acesso em: 10 set. 2014.

MACHADO, T. M.; MOLIN, J. P.; POVH, F. P.; SALVI, J. V. Metodologia para avaliação do desempenho de receptor de GPS de uso agrícola em condição cinemática. Engenharia Agrícola, Jaboticabal, v.30, n.1, p.121-129, jan./fev. 2010. Disponível em: <http://dx.doi.org/10.1590/S010069162010000100013>. Acesso em: 10 set. 2014.

MASSONI, P.F.S.; MARCHESAN, E.; GROHS, M., ROSO; R., COELHO, L.L.; MACHADO, S.L.O.; TELÓ, G.M.; DAL'COL LÚCIO, A. Influência de manejos pós-colheita do arroz irrigado sobre o banco de sementes de arroz-vermelho. Planta Daninha, Viçosa, v. 31, n. 1, p. 89-98, jan./mar. 2013. Disponível em: <http://www.scielo.br/scielo.php?pid=S0100$83582013000100010 \&$ script=sci_arttext $>$. Acesso em: 10 set. 2014.

MOLIN, J.P.; MILAN, M.; NESRALlAH, M. G. T.; CASTRO, C. N.; GIMENEZ, L. M. Utilização de dados georreferenciados na determinação de parâmetros de desempenho em colheita mecanizada. Engenharia Agrícola, Jaboticabal, v.26, p.759-767, 2006. Disponível em: <http://dx.doi.org/10.1590/S0100-69162006000300013>. Acesso em: 10 set. 2014.

MOLIN, J. P.; POVH, F. P.; DE PAULA, V. R.; SALVI, J. V. Método de avaliação de equipamentos para direcionamento de veículos agrícolas e efeito de sinais de GNSS. Engenharia Agrícola, Jaboticabal, v.31, n.1, p.121-129, jan./fev. 2011. Disponível em: <http://dx.doi.org/10.1590/S0100-69162011000100012>. Acesso em: 10 set. 2014. 
OLIVEIRA, D.; LOPES, E. S.; FIEDLER, N. C. Avaliação técnica e econômica do forwarder em extração de toras de pinus. Scientia Forestalis, Piracicaba, v.37, n.84, p.525-533, dez. 2009. Disponível em: <http://www.ipef.br/publicacoes/scientia/nr84/cap20.pdf>. Acesso em: 10 set. 2014

REYNALDO, E. F.; MOLIN, J. P. Proposta metodológica para avaliação de controlador automático de seções e pulverização. Engenharia Agrícola, Jaboticabal, v.31, n.1, p.111-120, jan./fev. 2011. Disponível em: <http://dx.doi.org/10.1590/S0100-69162011000100011>. Acesso em: 10 set. 2014.

ROMANO, L. N. Desenvolvimento de máquinas agrícolas: Planejamento, projeto e produção. São Paulo: Blucher Acadêmico, 2013. 310p.

SIMÕES, D.; FENNER, P. T. Avaliação técnica e econômica do forwarder na extração de madeira em povoamento de eucalipto de primeiro corte. Floresta, Curitiba, v.40, n.4, p.711-720, out./dez. 2010. Disponível em: <http://ojs.c3sl.ufpr.br/ojs/index.php/floresta/article/view/20323/13481>. Acesso em: 10 set. 2014.

SIMÕES, D.; SILVA, M. R. Análise técnica e econômica das etapas de produção de mudas de eucalipto. Revista Cerne, Lavras, v.16, n.3, p.359-366, 2010. Disponível em: <www.dcf.ufla.br/cerne/artigos/25-10-20108805v16_n3_artigo\%2011.pdf>. Acesso em: 10 set. 2014.

SIMÕES, D.; SILVA, M. R. Desempenho operacional e custos de um trator na irrigação pós-plantio de eucalipto em campo. Revista Ceres, Viçosa, v. 59, n.2, p.164-170, mar./abr. 2012. Disponível em: <http://dx.doi.org/10.1590/S0034-737X2012000200003>. Acesso em: 10 set. 2014.

SIMÕES, D.; SILVA, M. R.; FENNER, P. T. Desempenho operacional e custos da operação de subsolagem em área de implantação de eucalipto. Bioscience Journal, Uberlândia, v.27, n.5, p.692-700, set./out. 2011. Disponível em: <http://www.seer.ufu.br/index.php/biosciencejournal/article/view/11634/7874>. Acesso em: 10 set. 2014.

TOLEDO, A.; FURLANI, C. E. A.; SILVA, R. P.; LOPES, A.; DABDOUB, M. J. Comportamento espacial da demanda energética em semeadura de amendoim em latosolo sob preparo convencional. Engenharia Agrícola, Jaboticabal, v.12, n.30, p.459-467, maio/jun. 2010. Disponível em: <http://dx.doi.org/10.1590/S0100-69162010000300010>. Acesso em: 10 set. 2014. 